\title{
COMPRESSOR BLADE FATIGUE DIAGNOSTICS AND MODELLING WITH THE USE OF MODAL ANALYSIS
}

\author{
Mirosław Witoś \\ Michał Stefaniuk \\ Air Force Institute of Technology, \\ Warsaw, Poland
}

\begin{abstract}
This paper investigates the diagnostic and research aspects of the compressor blade fatigue. The authors have reviewed the characteristics of different modes of metal blade fatigue (LCF, $H C F, V H C F)$. The polycrystalline defects and impurities influencing the fatigue, along with their related surface finish techniques, have been taken into account. The experimental methods of structural health assessment have been considered. The Tip Timing (TTM), Experimental Modal Analysis (EMA) and Metal Magnetic Memory (MMM) provide information on the damage of the diagnosed object (compressor blade). It has been proven that the shape of resonance characteristics gives an ability to determinate if fatigue or a blade crack is concerned. Early damage symptoms, i.e. modal properties of material strengthening and weakening phases have been described. The experimental verification of the FEM model is presented based on a large body of experimental data collected by the author.
\end{abstract}

Keywords: compressor blade, damage, fatigue, modal analysis, lattice-spin coupling, FEM

\section{INTRODUCTION}

Many different fatigue failures (LCF, HCF and VHCF) could occur throughout the turbine engine life, Fig. 1. Fatigue cracks propagating in rotor blades, the incorrect control of the engine fuel system and the insufficient data on the loads affecting the bearing system, generally pose the flight safety hazard as well as adversely affect the engine life and reliability. Therefore, the AFIT continues to look for new methods of recognizing stochastic loads during the engine operation and their effects on the engine structural reliability. The paper presents three methods:

a) A non-contact blade-vibration measuring technique (tip timing method) [1-11], which is one of the most interesting methods of complex diagnosing of jet engines and a powerful tool of investigating dynamic phenomena in the running engine. The method has been used in the Polish Air Force since 1993 with the SNDL-1b/SPL-2b diagnosing system developed for the SO-3 engines. Since 1997 this method has been also used in the post-repair/post-overhaul acceptance tests.

b) An experimental modal analysis, which has been used as a sensitive NDT method during overhaul blade tests since 2008 [12].

c) A metal magnetic memory, which has been used as a sensitive observer of residual and applied stress, and continuous material damage [13-21]. 
These methods are a source of knowledge about the blade quality (design, production and overhaul) and real dynamics phenomena (correlation by modal properties), which have an effect on blade damage and fatigue differentiation. The knowledge has been used for the verification of the compressor blade FEM model.

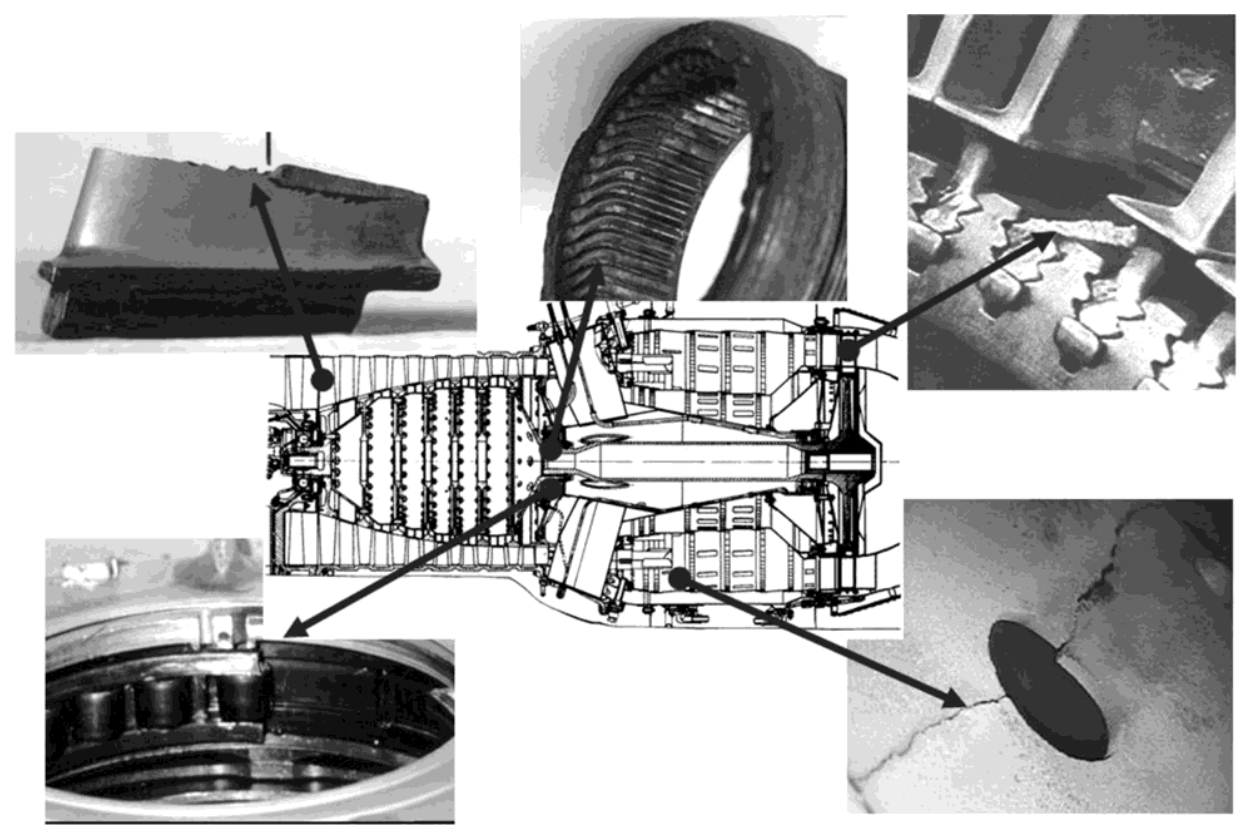

Fig. 1. Structural fatigue problems of turbine engines

\section{MOTIVATION}

In the years 1975-91 as many as 25 first-stage compressor blades of ten SO-3 engines suffered fatigue-attributable break-offs, which caused two accidents. The metallographic examination of damaged blades made from $18 \mathrm{H} 2 \mathrm{~N} 4 \mathrm{WA}$ steel proved that the crack initiation centers were located either on the leading edges $(55 \%)$ or on the blade-back surfaces $(45 \%)$, in the areas of nodal lines of the first mode vibration. Crack propagation occurred at low-level stresses (HCF problem) or high-level stresses (LCF problem), Fig.2. Fatigue fracture covering as much as 95\% of the blade's cross section was found in one of the blades. Furthermore, it was also found that erosion and corrosion, both occurring on the blade's face surface, as well as fine mechanical damage on the leading edge are stress concentrators [2]. The fatigue problem was also observed in titanium blades (Ti5.8Al-3.7Mo) in the TW3-117 engines in the years 2005-2007.

The gigacycle fatigue problem (VHCF) of the compressor blade was observed by foreign users, e.g. in Russia [22,23], Figure 2. Compressor blades run a risk of the VHCF problem because they count more than $3 \cdot 10^{9}$ cycles for $1^{\text {st }}$ flexible mode and more than $1 \cdot 10^{10}$ cycles for $1^{\text {st }}$ torsional mode during the time between overhauls (TBO). The high risk of the VHCF problem, with crack nucleation under the blade surface and stresses level below fatigue life stresses, concerns high resistant materials and blades made with surface finish techniques [24-26].

The blade which is not controlled in terms of fatigue:

- is a threat for service safety;

- limits aero-engine life time;

- increases maintenance costs.

The problem is also a great challenge for diagnostics engineers.

If blade fatigue is found, who is responsible for the problem? 


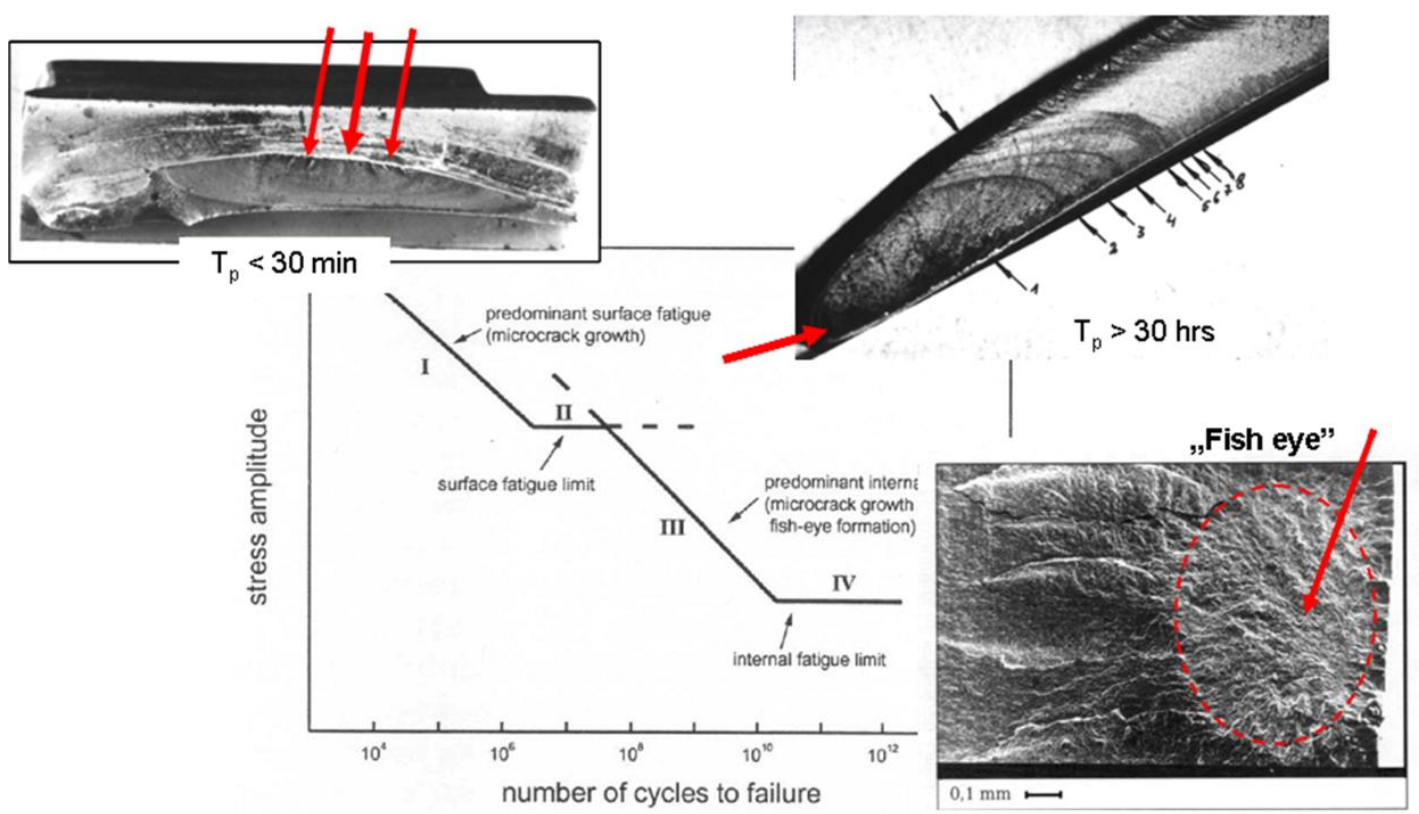

Fig. 2. Fatigue problems of compressor blade

The classical NDT methods (eddy current, ultrasound, magnetic and fluorescent) are quite ineffective for diagnosing a blade crack before damage occurs due to:

- crack gap closing during engine standstill (about 50\% of the crack area after $12 \mathrm{hrs);}$

- lack of reliable information about real operating conditions;

- lack of knowledge about early cracking symptoms and mechanisms;

- difficult access to tested blades (because of the inlet stator vane).

Another disadvantage of the NDT methods in use (during overhaul and service) is the fact that they offer no possibility of fatigue prognosis. This disadvantage is very important for the $1^{\text {st }}$ compressor blades of the SO-3 engine. The blades have design errors - too low the first-mode mistuning from the $2^{\text {nd }}$ rotational harmonic excitation. Therefore, too high stress and fast fatigue crack initiation can occur during operation. These conditions take place during the take-off phase when a foreign object enters the inlet or when the inlet icing occurs. Under such conditions, the time between crack initiation and blade damage can be shorter than the time of a single flight.

An intuitive diagnostic symptom of a blade crack is a change in its mode frequencies [27]. The crack propagation and blade break off occur at decreased frequency, the value of which depends on the crack centre's position and the loading. The blade frequency check offers an insufficient prognosis horizon. It is sufficient in the system monitoring only; for example, in the tip-timing method.

\section{TIP TIMING METHOD}

The tip timing idea consists in observing the displacement of the loaded component. In our case, it will be a rotating and vibrating blade. The observer is built onto a fixed part of the machinery. The measured signal contains:

- Aperiodic part $A(t)$ - average instantaneous rotational speed of perfect stiff rotor;

- Oscillating part $P(t)$ - resultant from: pitch errors, blade, rotor and disk vibrations and instantaneous rotational speed perturbations (from the engine control system, flow, g-force, clearance in a kinematic system, and torsional vibration);

- Noise and weak oscillating components $I(t)$.

$$
S(t)=A(t)+P(t)+I \mathbf{C}
$$


Therefore, it is possible to design a general-purpose observer for real operating conditions of rotating parts and obtain a complex inside into:

- Disadvantageous dynamic phenomena (flutter, stall, surge, resonance, load coupling);

- The influence of production, overhaul and maintenance real conditions on the level of malfunctioning and fatigue prognosis.

Blade vibrations and deflections are a source of a change in time-interval (measured) between flexible key phases. Time period signal would be measured with a frequency method, Figure 3.

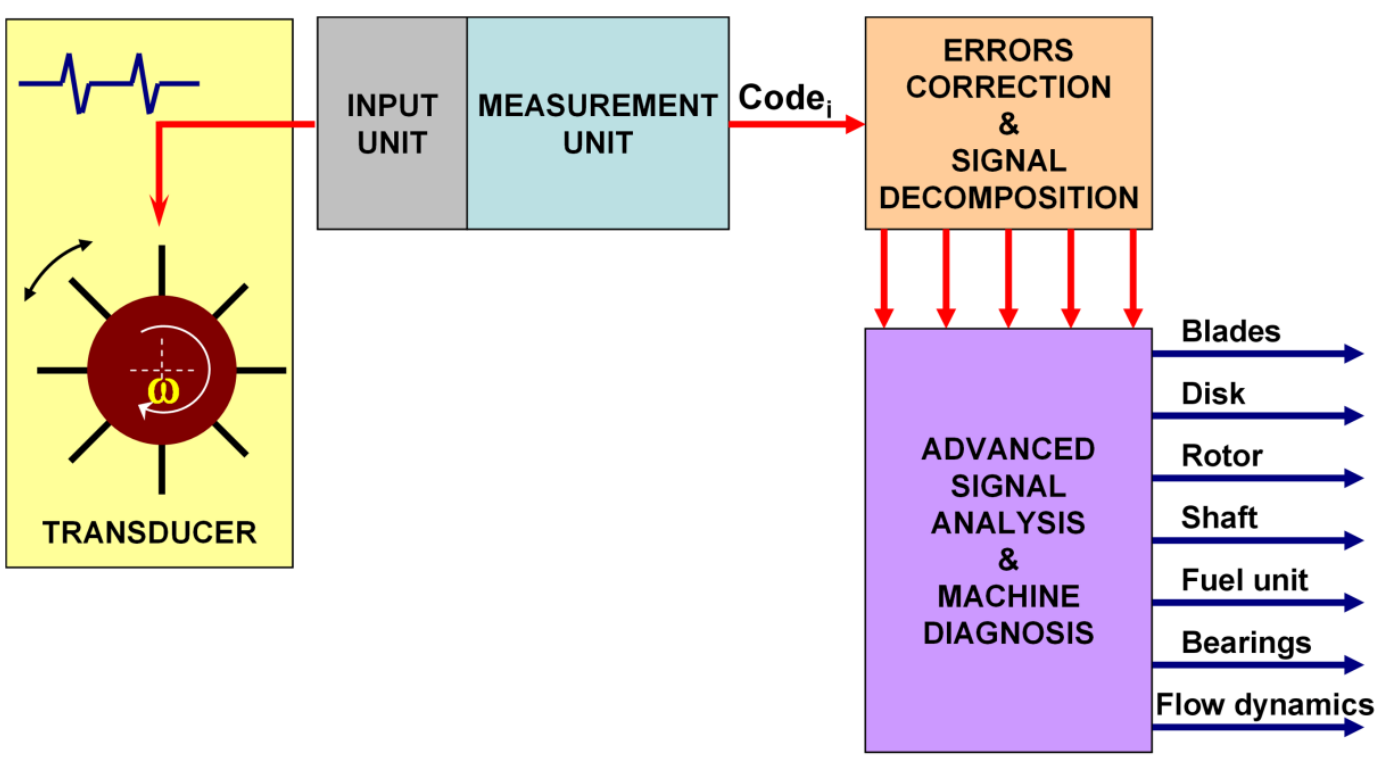

Fig. 3. Structure of a system for collecting information (based on the tip timing) [10]

The analyzed data - a number of pulses $\operatorname{Code}_{i}$ with clock frequency counting between the key phases (discrete time) includes three groups of variables to be identified in consequence of further numerical signal analysis,

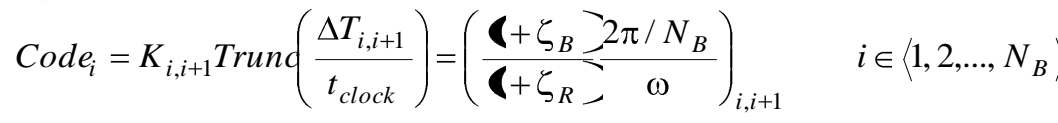

Where:

$N_{B}$ - number of blades, $\Delta T_{i, i+1}$ - time interval between two blade passes; $t_{\text {clock }}$ - time period of generator pulses; $K_{i, i+1}$ - error and disturbance factor $\left(\mathrm{K}_{\mathrm{i}, \mathrm{i}+1}=1\right.$ for data without error $), \zeta_{\mathrm{B}}-\mathrm{jitter}$ of blades group components, $\zeta_{\mathrm{R}}-$ jitter of rotor group components, $\omega$ - angular velocity of ideal rotor.

Every component of $S(\mathrm{t})$ and $C o d e_{i}$ is used for diagnostic purposes. An oscillating part $P(t)$ is a main carrier of diagnostic information about blades damage and dangerous dynamics phenomena. The scope of interest of the advanced tip timing data processing includes [1-11]:

- Vibration level of all blades at the same time,

- Disadvantageous dynamic phenomena,

- Blade health,

- Disk health,

- Blade stress,

- Engine health.

The tip timing method is not intended to measure: load, local displacement (strain) and local stresses in the blade. These can be estimated using TTM data and other numerical methods (GPA - Gas Path Analysis, FEM - Finite Element Method, CFD - Computational Fluid Dynamics, statistical methods) and knowledge about blade modal properties. 
The characteristic features of the TTM are:

- obtaining information about vibration and quasi-static blade deflection only once during 360 degree rotation;

- irregular signal sampling rate, affected by vibration parameters (such as amplitude, frequency and phase). The Nyquist-Landau law describes discrete-time information;

- periodic measurement data structure - data can be illustrated with the matrix with $N_{\mathrm{B}}$ columns (number of blades) and rows that represent each full 360-degree cycle of a rotor;

- the signal oscillating parts are not connected with blade vibration. There are two groups of oscillating parts of a signal: synchronized and non-synchronized with the rotor rotational frequency;

- observation of the effects of coincident amplitude modulation (AM), frequency modulation $(\mathrm{FM})$ and phase modulation (PM) if there are oscillating parts in a signal.

\subsection{The idea of the expert system}

The major concept of the expert analysis of engine health is the projection of actual characteristics of some engine systems (e.g. blades, a fuel system or a bearing system) in the phase space described with the following equation:

$$
\forall i \in \mathbf{\ell}, 2, \ldots, m-H V=\left(\operatorname{Par}, \frac{d P a r_{i}}{d t}, \frac{d^{2} P^{-} r_{i}}{d t^{2}}\right)_{m} \in T R \Rightarrow \text { ENGINE OPERATIONAL }
$$

Where: $m$ - the number of analysed signals, Par - analysis signal, $T R$ - technical requirements

In the simplest case, having only engine rotational speed, the engine operational range is described in a certain three-dimensional (3D) space. The actual point of engine performance is monitored not only based on the transient value of rotational speed but also based on the first and second derivatives of rotational speed, which represent some directions in which parameters (and excitations that accompany them) keep changing.

To solve this problem, the qualitative evaluation of applicability of the tip timing method was conducted in 1987-1993. Particular attention was paid to the possibility of estimating the blade health (crack initiation and propagation) on a running engine [2]. Signal components are obtained with the narrow-band filtering and AM/FM demodulation. They are very useful to expert analysis of the health of the engine itself and the $1^{\text {st }}$ stage compressor blades, the engine fuel system and the bearing system $[6,11]$.

Blade vibrations are shown in the form of phase distributions as points of the phase trajectory crossing the phase plane, Figures 4 i 5 . A characteristic feature of the method is the capability to obtain lasting information about a total number of modal frequency periods between two subsequent points on the phase trajectory crossing the phase plane, with the basic modal parameters of the blades preserved. This phenomenon enables detection of the HCF crack initiation and propagation in the blade during the engine operation.

\subsection{Examples}

The object under scrutiny has been the $1^{\text {st }}$ stage compressor blade ( 28 blades made from $18 \mathrm{H} 2 \mathrm{~N} 4 \mathrm{WA}$ steel, each $100 \mathrm{~mm}$ long, chord $37 \mathrm{~mm}$, twisted by the angle of $38^{\circ}$ ). Frequencies of three subsequent modes of blade vibration were as follows (average values): $350 \mathrm{~Hz}$ and $1380 \mathrm{~Hz}$ (bending vibration), $1890 \mathrm{~Hz}$ (torsional vibration).

\section{Synchronous resonance}

During examination with a strain gauge no evident symptoms of interrelationships between the disk and blade vibrations were observed - compressor stages are of compact design. However, it 
was observed that within the take-off range of the SO-3 engine operation ( $\mathrm{n}=15600 \mathrm{rpm})$, synchronisation of blade vibration with forces from the $2^{\text {nd }}$ harmonic of the rotational speed $\left(\mathrm{f}_{1 \text { mode }}\right.$ $=520 \mathrm{~Hz}$ ) may occur, Figure 4.b). The phenomena such as those observed e.g. after some foreign object (bird, ice) has been deposited on the stator blade-ring, induce blade vibration up to some dangerous levels, where the material yield point is reached and exceeded, and quick initiation and propagation of the LCF and HCF crack occur. Under such conditions of blade operation, time of safe operation of any turbojet engine may be much shorter than one flight/mission of an aircraft.

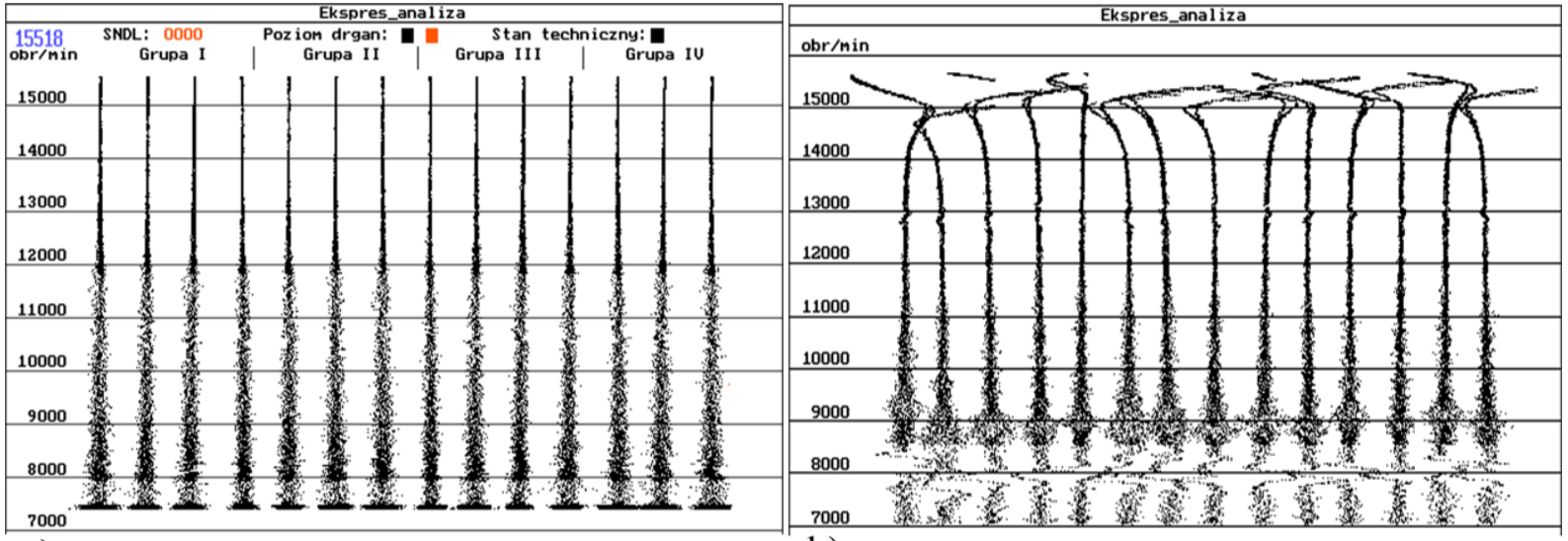

a)

b)

Fig. 4. How foreign-matter depositions may affect the level of stress in the SO-3's $1^{\text {st }}$ stage compressor blades [2]: a) model amplitude-phase spectra of the $1^{\text {st }}$ compressor blade; b) effect of foreign matter in compressor inlet

\section{The blade cracking}

After the analysis of the destructive testing results (controlled propagation of blade cracking under normal conditions of operating of the SO-3 engine) it was found that:

- during the blade cracking initiation (no open crack visible on the blade surface) only the change in the $B$ factor of the dynamic increment of the blade vibration frequency is seen, Figure 5.a), while the frequency of the blade's free vibration $f_{B}(0)$ is constant

$$
f_{B}(n)=\sqrt{f_{B}(0)^{2}+B n^{2}}
$$

- the occurrence of a blade crack decreases in the range of excitations from the rotationalspeed II harmonic by $1000 \mathrm{rpm}(\Delta \mathrm{f}=16.6 \mathrm{~Hz})$, Figure 5.b). At the moment, frequency (the $1^{\text {st }}$ mode) of the blade's free vibration changed by less than $3 \mathrm{~Hz}$;

- when the crack reaches about $30 \%$ of the blade profile, an evident reduction in free vibration frequency and a decrease in the range of excitations from the rotational-speed III harmonic were observed, Figure 5.c);

- just before the blade break-off (about $65 \%$ of the profile for the crack from the leading edge, $95 \%$ of the profile for the crack from the back of the blade), an evident effect of stiffening due to centrifugal forces was observed, Figure 5.d). Changes in the dynamic scale inflicted by the broken blade are comparable with those in other dynamic scales (the influence of the engine's rotational speed). 


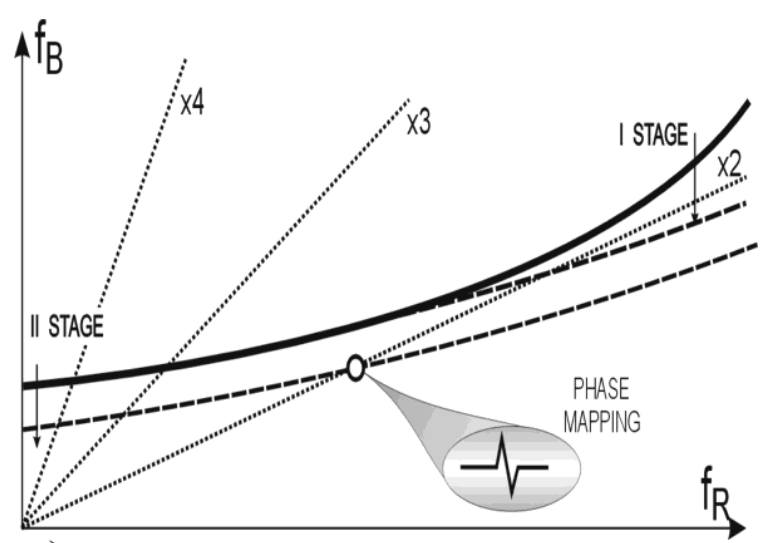

a)

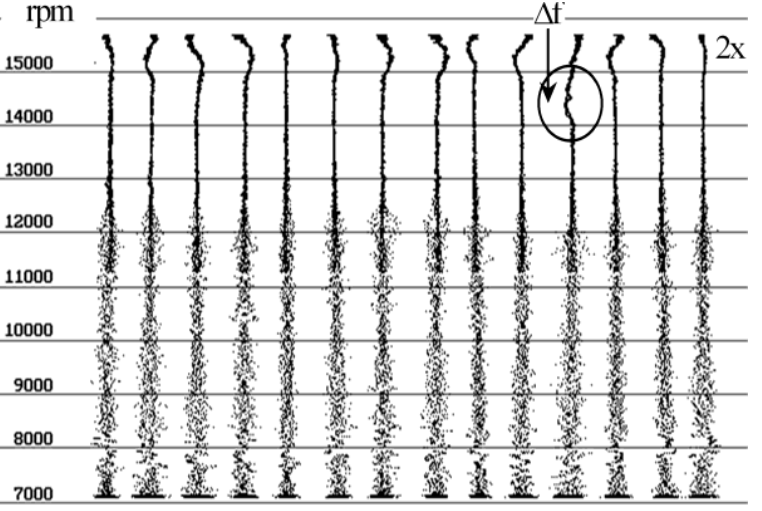

b)

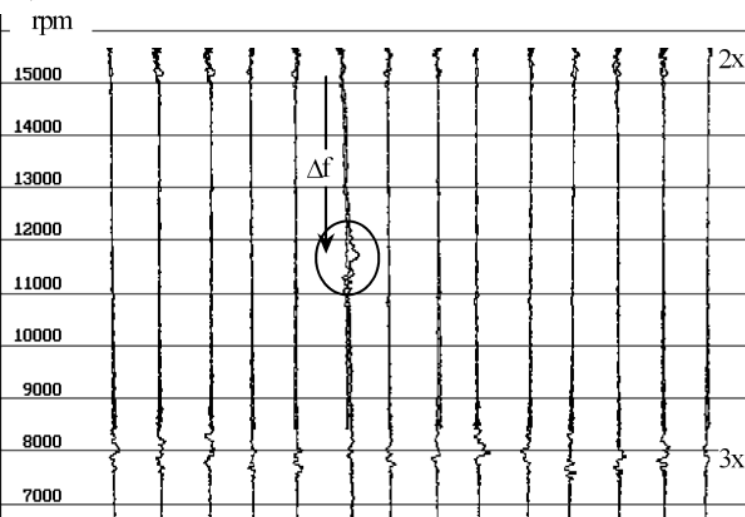

d)

c)

Fig. 5. The effect of blade cracking as phase representation of blade vibration [2]:

a) blade frequency plotted in the Campbell diagram; $b)$ the first stage of blade cracking

- changes only $B ; c)$ the second stage of blade cracking - changes $f_{B}(0)$ and $B(L P F)$;

d) final stage of blade cracking -5 minutes before break (LPF)

The representative one-hour profile of the engine mission used for the bench test has comprised:

- starting of the engine,

- engine warm-up,

- ground idle running ( $3 \times$ 4.5 min),

- running the engine within the take-off range of speed (4.5 min)

- running the engine within the cruising range of speed (4.5 min)

- eleven full acceleration/deceleration cycles (ground idle - take-off range of speeds - ground idle),

- half-way accelerations/decelerations within the range: idle-12000 rpm (3x $4.5 \mathrm{~min}$, 5 cycles/min),

- half-way accelerations/decelerations within the range: $12000 \mathrm{rpm}$ - take-off range (3x 4.5 min, 5 cycles/min),

- engine cooling,

- stopping the engine.

In such a mission profile, the blade crack propagation from the crack initiation down to the blade break-off took more than $30 \mathrm{hrs}$ for the normal level of excitations. On the other hand, it did not take more than 20 minutes (about 624000 blade cycles at the $1^{\text {st }}$ mode frequency) of the engine running within the take-off range of speed and at a high level of stress (deposition of some foreign object in the inlet). It has been proven that the TTM gives credible prognosis for 50 engine work hours (over 9x107 HCF and $100 \mathrm{LCF}$ cycles, 1/8 TBO). It has been also proven $[11,12]$ that TTM symptoms of the cracking are closely related to: 
- the strengthening phase - the quality factor of the resonance system increases together with the friction mode frequency;

- the weakening phase - growth in the resonance curve asymmetry and growth in nonlinearity.

Nowadays, these symptoms are not used in the SNDE-1b/SPE-2b system. They provide a capability of broadening prognosis horizon.

\section{THE EXPERIMENTAL MODAL ANALYSIS METHOD}

Experimental modal analysis is an effective aid in solving blades' fatigue problems. It allows answering the question: "Why does a blade crack?", not only: "Is it cracked?". The modal parameters of all the analysis modes (within the frequency range of interest) constitute a complete dynamic description of the blade structure:

blade material;

2s blade geometry;

25 the influence of surface treatment and adding protection coating;

25 technical health (structural heterogeneity, crack and fatigue).

The characteristic feature of blade vibration measurement on a modal excitation system is knowledge of both excitation force and the blade's response to it. This is why it is possible to identify blade modal properties for respective modes.

The broadband identification (up to $20 \mathrm{kHz}$ ) of modal properties of a compressor blade made of 18H2N4WA steel and Ti5.8Al-3.7Mo titanium alloy, has been made on the PSV-400 Polytec scanning vibrometer [28] and low power PZT exciter, Figure 6.

The identification of early fatigue and cracking symptoms of these blades has been made on the B\&K electro-dynamic exciter 4802T. The experimental stand used during the SO-3 and TW3-117 engine overhauls included:

- the MTI Instrument laser measurement system MicroTrack ${ }^{\mathrm{TM}} \mathrm{II}$ with CMOS measurement head LTC-120-40 [29];

- the Vibration Research Corporation VR-8500 controller that includes 24 bit A/D and D/A converters, and RISC processor [30];

- the Vibration Research Corporation VibrationView software to control the exciter, data acquisition and analysis [30].

The sensitivity of the measurement system is $100 \mathrm{mV} / \mathrm{mm}$.

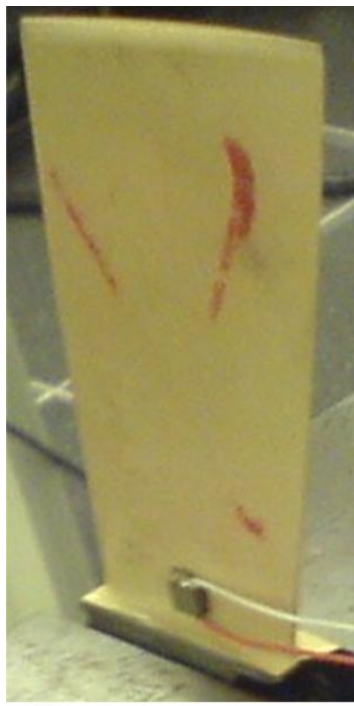

a)

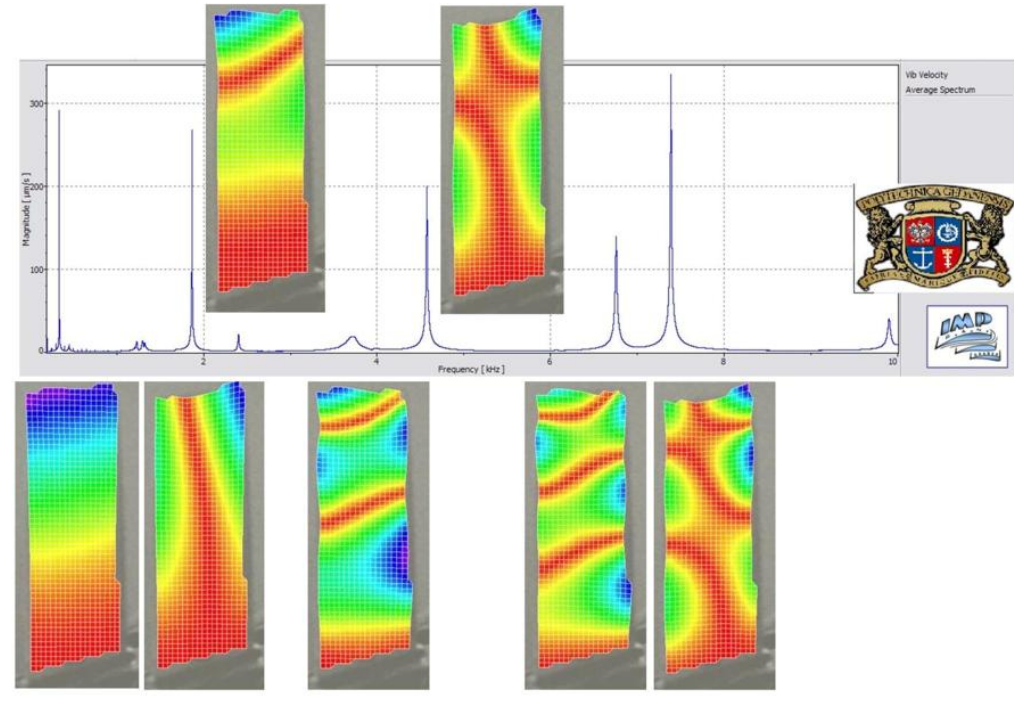

b)

Fig. 6. The broadband modal identification of $S O-3$ compressor blade: a) PZT exciter position on the $1^{\text {st }}$ stage blade; $b$ ) results of a laser measurement (987 points) [31] 
Experiments have been performed at four stages, in which:

- the measurement method has been verified,

- blade cracking symptoms have been identified,

- early symptoms of fatigue have been identified,

- new diagnostic symptoms have been verified for the titanium blade.

It has been proven that measurement technique used (MTI laser head) guarantees reliable modal results when vibration amplitude is higher than $2 \mu \mathrm{m}$. The reliable resonance curve shape during sine test was obtained for force frequency: $2.5 \mathrm{~Hz} / \mathrm{min}$ - for $1^{\text {st }}$ flexible mode $\left(1 \mathrm{~F}, \mathrm{Q}_{\mathrm{s}}>350\right)$ and $1.0 \mathrm{~Hz} / \mathrm{min}-$ for $1^{\text {st }}$ torsion mode $\left(1 \mathrm{~T}, \mathrm{Q}_{\mathrm{s}}>1000\right)$. Such a stand provides capability to make precise measurements with an exact test profile and frequency step. The measurement system gives almost laboratory accuracy. This is why it enabled [12]:

- Precise identification of the blade modal properties in measured frequency range;

- Analysis of the metrological factors influence on recorded resonance characteristics;

- Analysis of the modal parameters trends observed during fatigue tests.

The modal properties identification (sine test) was based on the transition function

$$
G(\omega)=\frac{Y(\omega)}{X(\omega)} \quad\left[\frac{m}{m}\right]
$$

Where: $X(\omega)$ - displacement of an exciter head (blade root); $Y(\omega)$-displacement of a blade tip.

\subsection{Modal properties of a defect-free (non-cracked) blade}

In the case of a defect-free (healthy) blade, the resonance characteristics of particular modes were gained, which could be well described with a model of a single-degree-of-freedom linear system (SDOF) - of mass $m$ suspended on a spring with spring rate $K$ and viscous damping $C$. The SDOF model is described by:

$$
\begin{aligned}
& m \frac{d^{2} y(t)}{d t^{2}}+C \frac{d y(t)}{d t}+K y(t)=F(t) \\
& F(t)=A(\omega) \sin (\omega t) \\
& y(t)=B(\omega) \sin \mathbf{p} t+\varphi
\end{aligned}
$$

Characteristics of subsequent modes remain continuous under resonance conditions and exhibit good symmetry around the resonance frequency (within the band-width of $3 \mathrm{~dB}$ ), Figure 7 . The blade displacement at the measuring point can be described with:

- vibration amplitude

$$
b(\omega)=\frac{y_{s t}}{\sqrt{\left[-\left(\frac{\omega}{\omega_{o}}\right)^{2}\right]^{2}+\left(\frac{\delta}{\pi} \frac{\omega}{\omega_{o}}\right)^{2}}}
$$

- vibration phase angle

$$
\varphi\left(\frac{\sigma}{\omega}=\arctan \left(\frac{\delta}{\pi} \frac{\omega}{\omega_{o}} / 1-\left(\frac{\omega}{\omega_{o}}\right)^{2}\right)\right.
$$

where, $\omega_{0}-\mathrm{a}$ free vibration frequency, $\delta-$ a logarithmic damping decrement. 


\subsection{Diagnostic symptoms of a cracked blade}

When analyzing the resonance curve shape we can observe how different it is for the cracked blade, Figure 7 . The blade has all nonlinear properties [12,32,33], which are described by a nonlinear 2DOF model. Close to the resonance frequency it is possible to observe two branches of characteristics: resonance attractor $-S_{r}$, and non-resonance attractor $-S_{n}$, and jumps between them. The shape of a cracked-blade's resonant curve is affected by the blade's material and conditions existing on the edge of the crack gap. The characteristic curve is sloped to the left (towards lower frequencies) for the crack with material weakening. On the other hand, for the gap with material hardening, the curve is sloped to the right (towards higher frequencies). The knowledge of resonant curve inclination is essential for correct interpretation of measurements, including correct identification of the resonant and non-resonant branches. During one-sided test, we observe the "asymmetry" resonance curve with seeming quality factor decreases. Resonance frequency and characteristics are functions of the blade amplitude. There are no asymmetry symptoms for:

- small loads that do not develop an open crack. Asymmetry is growing with a load increase;

- a notch on a blade, which was used as a simplified crack model (no friction at a notch hole). No friction in the notch modeled blade is a source of other differences in modal properties, Table 1, and fatigue (JCF phenomena).

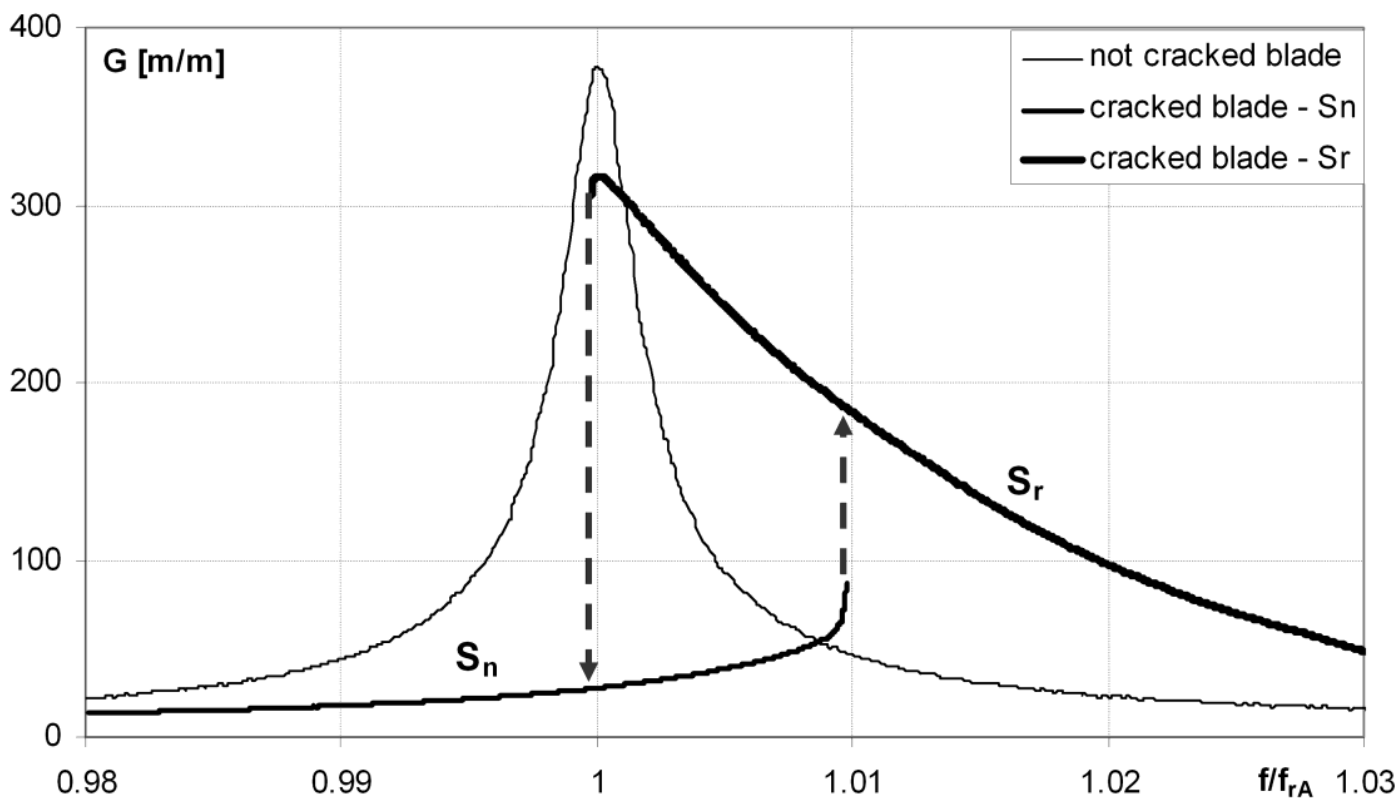

Fig. 7. The effect of a crack on the $1^{\text {st }}$ mode characteristics shape (steel blade, $a=19.62 \mathrm{~m} / \mathrm{s}^{2}, f_{r A}-$ frequency of amplitude resonance)

Table 1. Blade with $11 \mathrm{~mm}$ length damage (starting from $\mathrm{TE}$ ) placed $20 \mathrm{~mm}$ from lock

\begin{tabular}{|c|c|c|c|}
\hline \multirow{2}{*}{ Blade } & \multicolumn{3}{|c|}{ Frequency change (Hz) } \\
\cline { 2 - 4 } & $\mathbf{1}^{\text {st }}$ mode & $\mathbf{2}^{\text {nd }}$ mode & $\mathbf{3}^{\text {rd }}$ mode \\
\hline Cracked & -12 & +7 & -27 \\
\hline Notched (no friction) & -13 & -5 & -80 \\
\hline Difference (\%) & $\mathbf{- 0 . 2 8}$ & $\mathbf{- 0 . 8 6}$ & $\mathbf{- 2 . 7 3}$ \\
\hline
\end{tabular}

The obtained characteristics of the cracked blade cannot be described with a single-degree-offreedom (SDOF) linear model. The blade crack forms a two-degrees-of-freedom (2DOF) non- 
linear system for any form of blade vibration. The equivalent linear equation that satisfies the nonlinear equation with accuracy $\varepsilon$ takes the following form:

$$
\frac{d^{2} y}{d t^{2}}+2 h_{\varepsilon}(b) \frac{d y}{d t}+\alpha_{\varepsilon}^{2}(b) y=\varepsilon p \cos \varphi t_{-}^{-}
$$

Where: $\varepsilon$ - small parameter, $p$ - amplitude of the exciting force, $b$ - steady-state vibration amplitude, $\alpha_{\varepsilon}(b)$ - equivalent natural (free-vibration) frequency, $h_{\varepsilon}(b)$ - equivalent elementary damping coefficient.

The measured and analyzed parameters of the blade are described with the following relationships:

- vibration amplitude

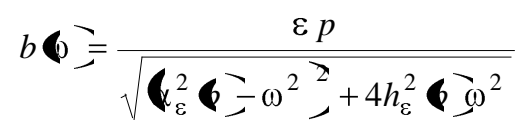

- resonance frequency

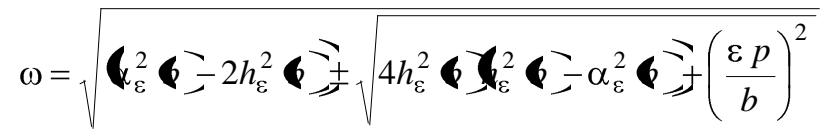

- vibration phase angle

$$
\varphi(\omega)=\arctan \left[\frac{-2 h_{\varepsilon}(b) \omega}{\alpha_{\varepsilon}^{2}(b)-\omega^{2}}\right]
$$

\subsection{Early fatigue identification}

The LCF and HCF data analyses showed that blade modal properties could be used to observe the material strengthening phase $[12,32,34]$. Increase in the $1^{\text {st }}$ mode resonance frequency of approx. $0.4 \%$ is a symptom of the growth in the initial resonance system quality factor, Figure 8. This phase can be described with the linear SDOF model. The orientation indicator of maximum cyclic material strengthening is $\mathrm{R}_{\mathrm{m}} / \mathrm{R}_{\mathrm{e} 0.2}$ (like as for metal magnetic memory NDT according to ISO-15242) [14].

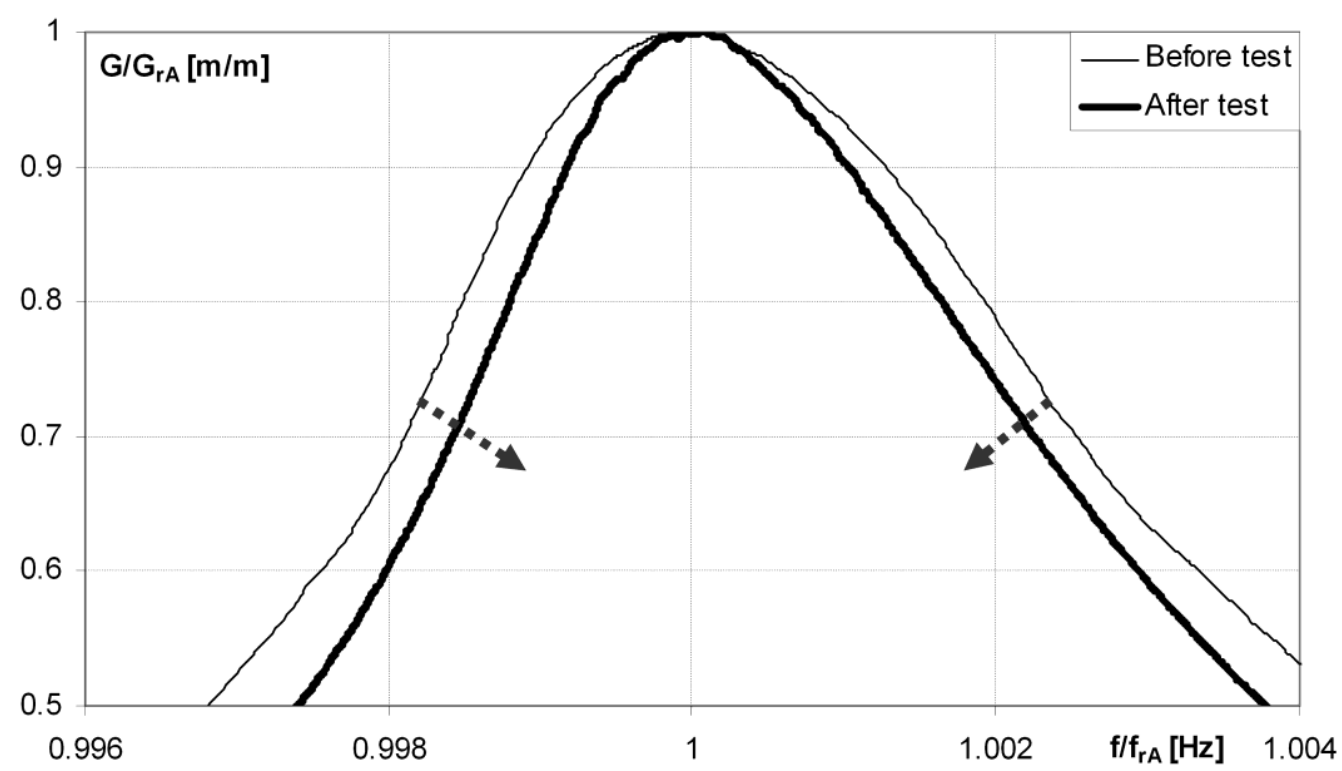

Fig. 8. Changes in modal parameters during material strengthening phase 
The growing asymmetry of the resonance curve was observed only in the final fatigue phase; it preceded the $1^{\text {st }}$ mode frequency decrease, Figure 9. The speed rate of its development was conditioned by the load history of the blade. The asymmetry is a symptom of the material weakening phase $[12,32,34]$. The speed rate of the resonance curve asymmetry development, from the very first symptom of an open crack, is determined by the blade loading history.

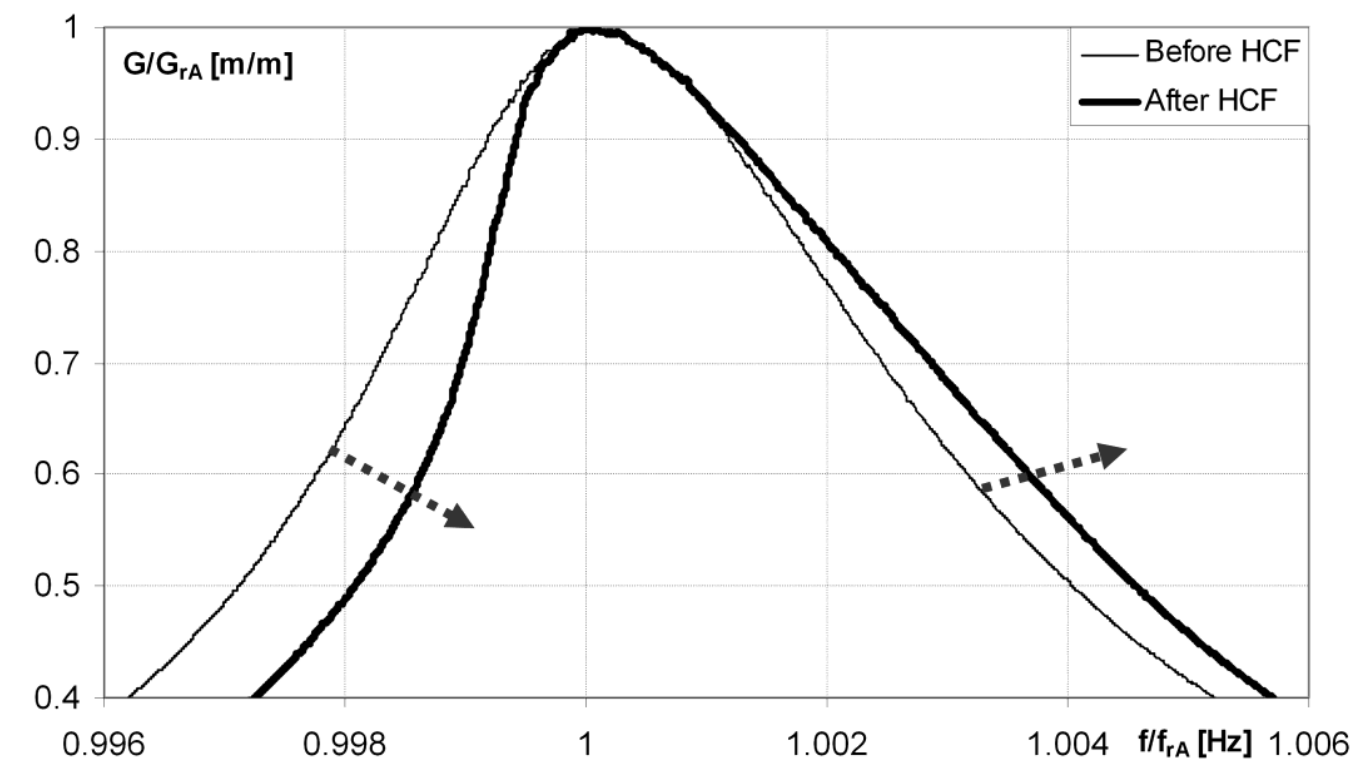

Fig. 9. Changes in modal parameters during material weakening phase $\left(\delta_{r A}=-0.5 \mathrm{~Hz}\right)$

\subsection{JCF phenomena}

Influence of the cracked blade's resonant curve discontinuity on the propagation rate was investigated for blades made from titanium alloy. It was found that in the case of constant frequency input (HCF tests without fine tuning to current resonant frequency), the characteristic curve sloping to right and resonant curve discontinuity help stop the crack propagation.

Discontinuity of the resonant curve (blade pulse input discharge and load even for constant external load) is a source of very fast crack propagation during the frequency transient phase - the phenomenon is called Jump Cycle Fatigue (JCF). This phenomenon is a reason for the serial material tearing during the decrease in excitations frequency, observed in the unstable phase of cracking, Figure 10. Those observations are fundamental to the prognosis of crack propagation velocity and determination of the safe prognosis horizon for the blade operation.
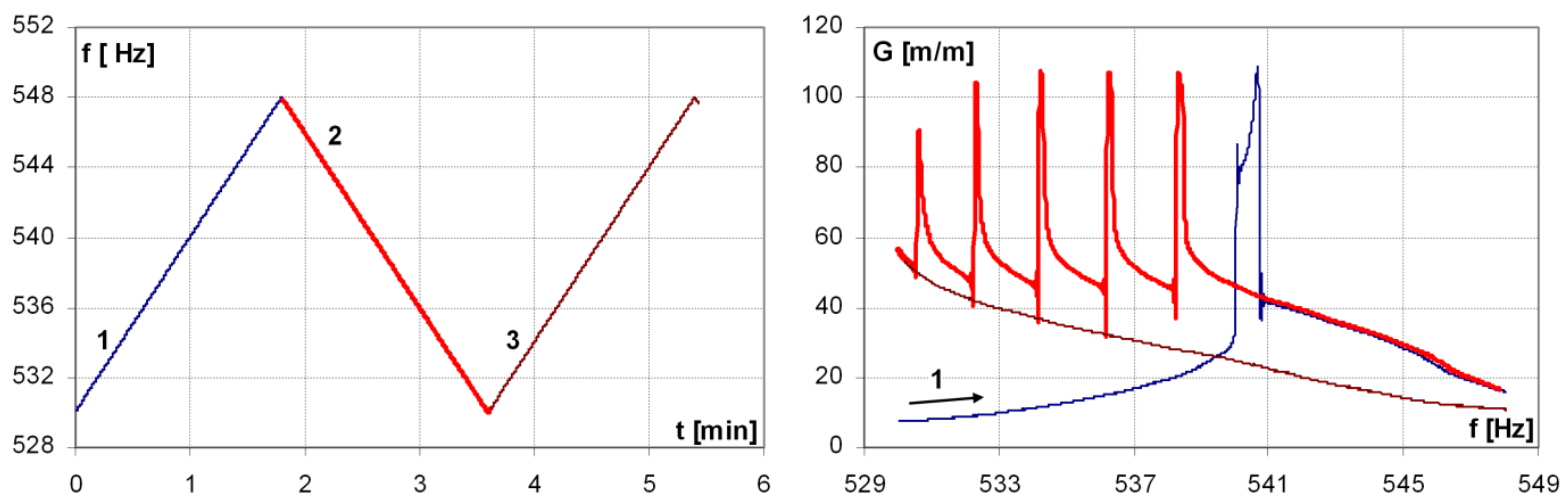

Fig. 10. JCF phenomenon for a cracking blade (blade with Ti5.8Al-3.7Mo, sine sweep) 


\section{THE METAL MAGNETIC MEMORY METHOD}

Modal properties of the compressor blade $(K, C)$ are correlated with local magnetic properties of its material by grain and lattice-spin coupling (magneto-mechanical effects i.e. Villari effect, $\Delta \mathrm{E}$ effect, stress magnetization and spontaneous magnetization of ferromagnetic in the Earth field) [13,34-37]. Zones RSC of local residual stress concentration, plastic, material anisotropy (mechanical and magnetic) and dislocation concentration are potential places of cracking nucleation and local magnetic anomaly, Figure 11.
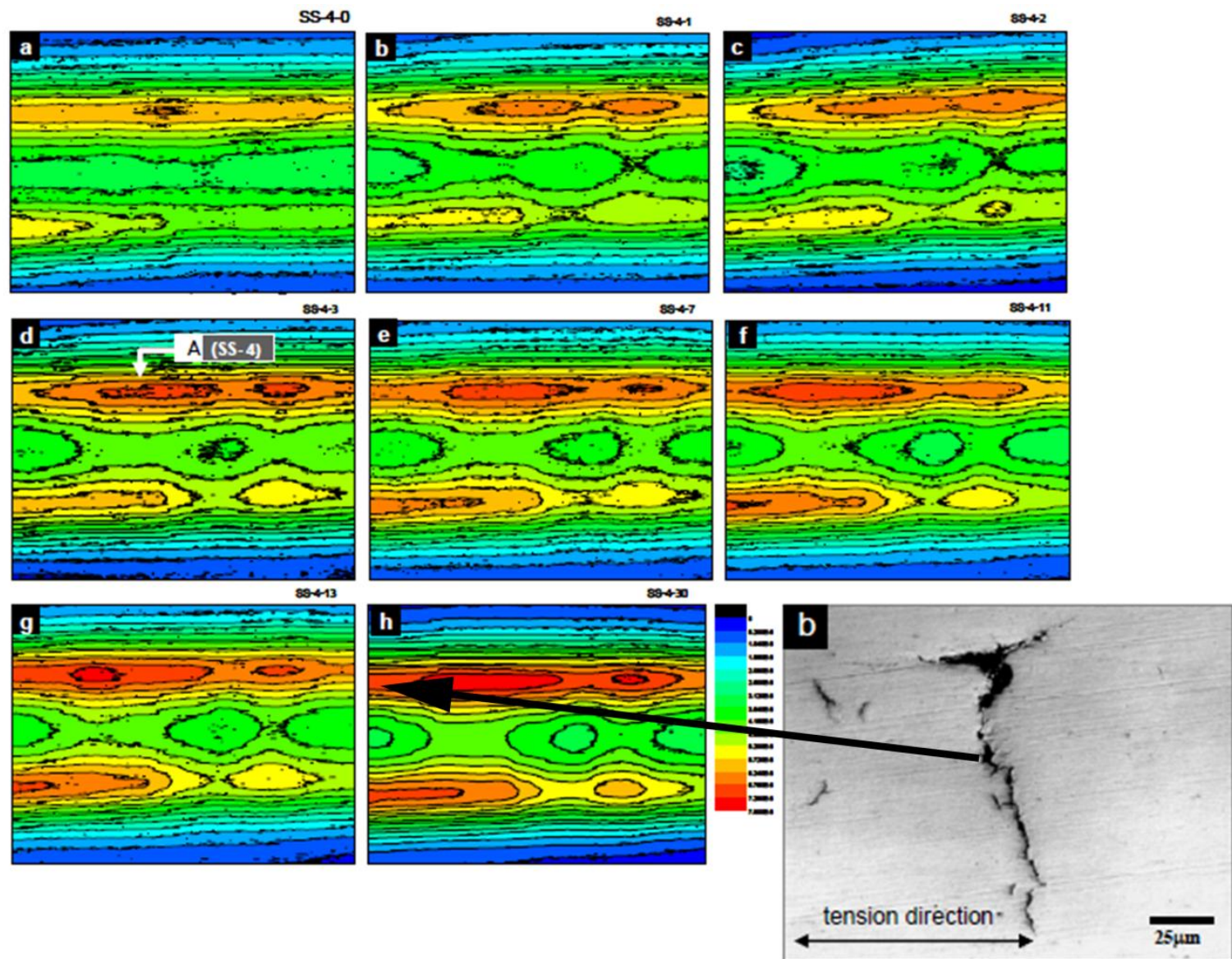

Fig. 11. Correlation between TEM microstructure and SQUID magnetogram during HCF test of 430 stainless steel after [34]: TEM: $0 ; 1 \cdot 10^{3} ; 1 \cdot 10^{4} ; 2 \cdot 10^{4} ; 4 \cdot 10^{5} ; 5 \cdot 10^{5}$ cycles; SQUID: $0 ; 1 \cdot 10^{3} ; 5 \cdot 10^{3}$; $2 \cdot 10^{4} ; 1,2 \cdot 10^{5} ; 1,45 \cdot 10^{5} ; 2,8 \cdot 10^{5} ; 9,2 \times 10^{4}$ cycles. SQUID scanning area $10 \times 20 \mathrm{~mm}$

The RSC zones are searched by a passive observer - the metal magnetic memory method (MMM). Stress, strain (elastic and plastic) and dislocation density change material magnetization $\boldsymbol{M}$ and the external magnetic field $\boldsymbol{H}$ in the vicinity of the blade surface (material permability $\mu$ ).

For small elastic deflection (strain) of the blade, the magneto-mechanical effects are described by the reversible thermodynamic relation [39]:

$$
\mu_{0}\left(\frac{\partial \mathbf{M}}{\partial \boldsymbol{\sigma}}\right)_{\mathbf{H}}=\left(\frac{\partial \mathbf{B}}{\partial \boldsymbol{\sigma}}\right)_{\mathbf{H}}=\left(\frac{\partial \lambda}{\partial \mathbf{H}}\right)_{\boldsymbol{\sigma}}
$$

where, $\mu_{0}$ - magnetic permeability of free space,

$\left(\frac{\partial \mathbf{M}}{\partial \boldsymbol{\sigma}}\right)_{\mathbf{H}},\left(\frac{\partial \mathbf{B}}{\partial \boldsymbol{\sigma}}\right)_{\mathbf{H}}$ - reversible isofield magneto-mechanical coefficients,

$\left(\frac{\partial \lambda}{\partial \mathbf{H}}\right)_{\sigma}$ - reversible isostress magnetostrictive coefficient. 
The magneto-mechanical effects are partially irreversible for elastic strain and RSC (source of stress magnetization and local magnetic anomaly).

The RSC are searched by the criterion of:

$$
R S C \text { if }\left[\boldsymbol{H}_{z}=H_{0} \text { - and }\left(\frac{d H_{x}}{d x}=0\right)\right]
$$

Where: $H_{z}$ - the components of the magnetic field perpendicular to the researched surface of the element; $H_{\mathrm{x}}$ - the components of the magnetic field contiguous to the researched surface and perpendicular to RSC; $H_{0}$ - reference level (typical $\mathrm{H}_{0}=0 \mathrm{~A} / \mathrm{m}$ ).

Potential possibilities of MMM were tested during active and passive experiments with the use of the GM-04 magnetometer and IKN-1M-4 stress concentration recorder. A very good relation has been observed between the MMM results and blade node lines after LCF tests [21]. Local magnetic anomaly has been also observed near the close crack gap after HCF tests, Figure 12. Nevertheless, the most interesting phenomenon is a non-destructive detection of stress prehistory, Figure 13.

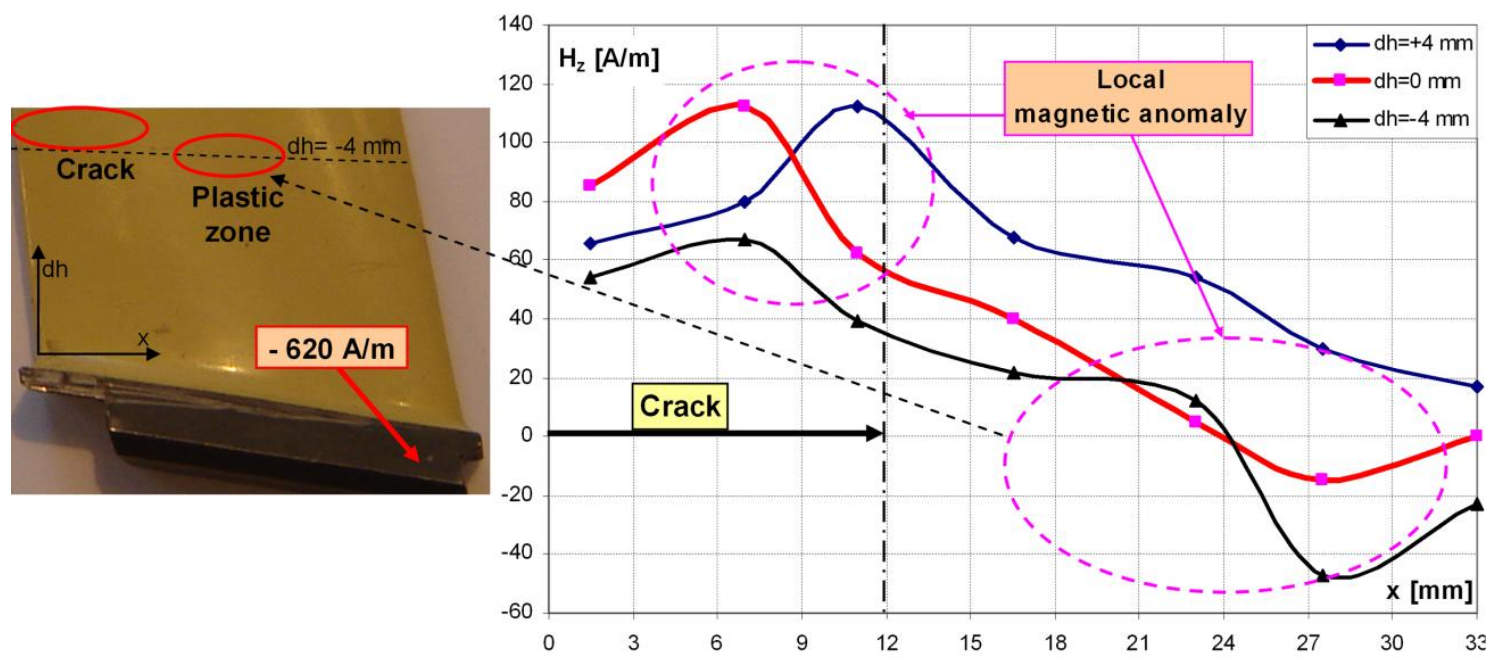

Fig. 12. MMM symptoms of cracked blade with close gap (after HCF test)
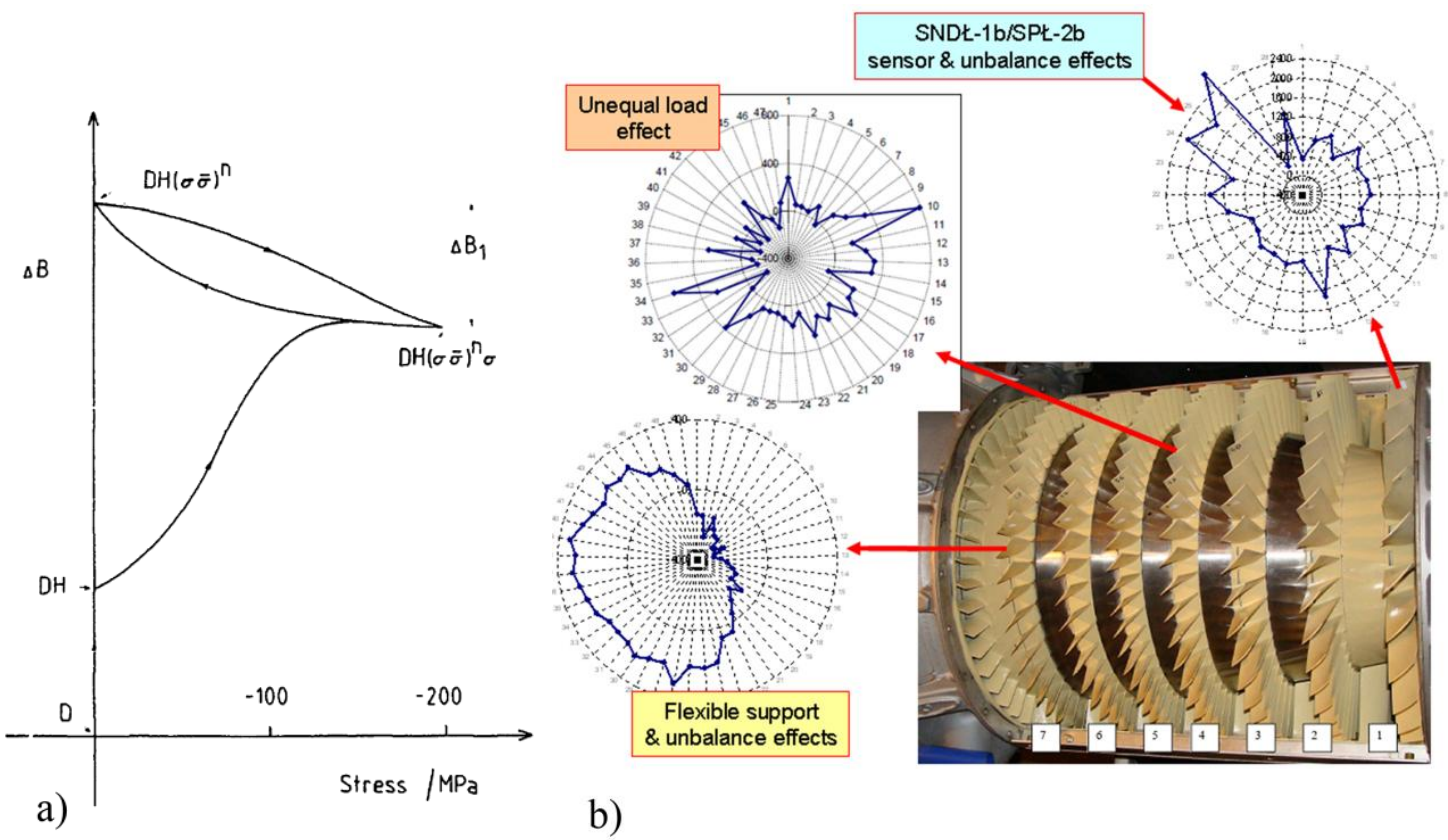

Fig. 13. Detection of stress prehistory: a) irreversible process of stress magnetization [38]; b) identification of blade fatigue risk [31] 


\section{THE NUMERICAL ANALYSIS}

A defect-free compressor blade has been modeled by Unigraphics NX 4.0, FEM MD.NASTRAN/MD.PATRAN. The numerical modal analysis used:

- linear material constitutive model;

- hexahedral mesh, 4526 elements and 6113 nodes. Fillets and edge curvatures were included;

- material: steel $\mathrm{E}=204 \mathrm{GPa}$ with internal (material) damping $\mathrm{c}=0,005$;

- measurement point $5 \mathrm{~mm}$ from the leading edge, orientation perpendicular to the blade surface.

A comparison between experimental and numerical results is presented in Figure 14. An evident difference between the curves proves that:

- the magnification factor varies with frequency,

- frequency and strain amplitude dependent damping should be introduced in the FEM model.

\subsection{Internal damping}

Three primary mechanisms of damping $Q^{-1}=\delta / \pi$ are important in the study of mechanical systems [40], for instance of compressor blades:

- internal damping (of material),

- structural damping (at joints and interfaces),

- fluid damping (through fluid - structure interactions).

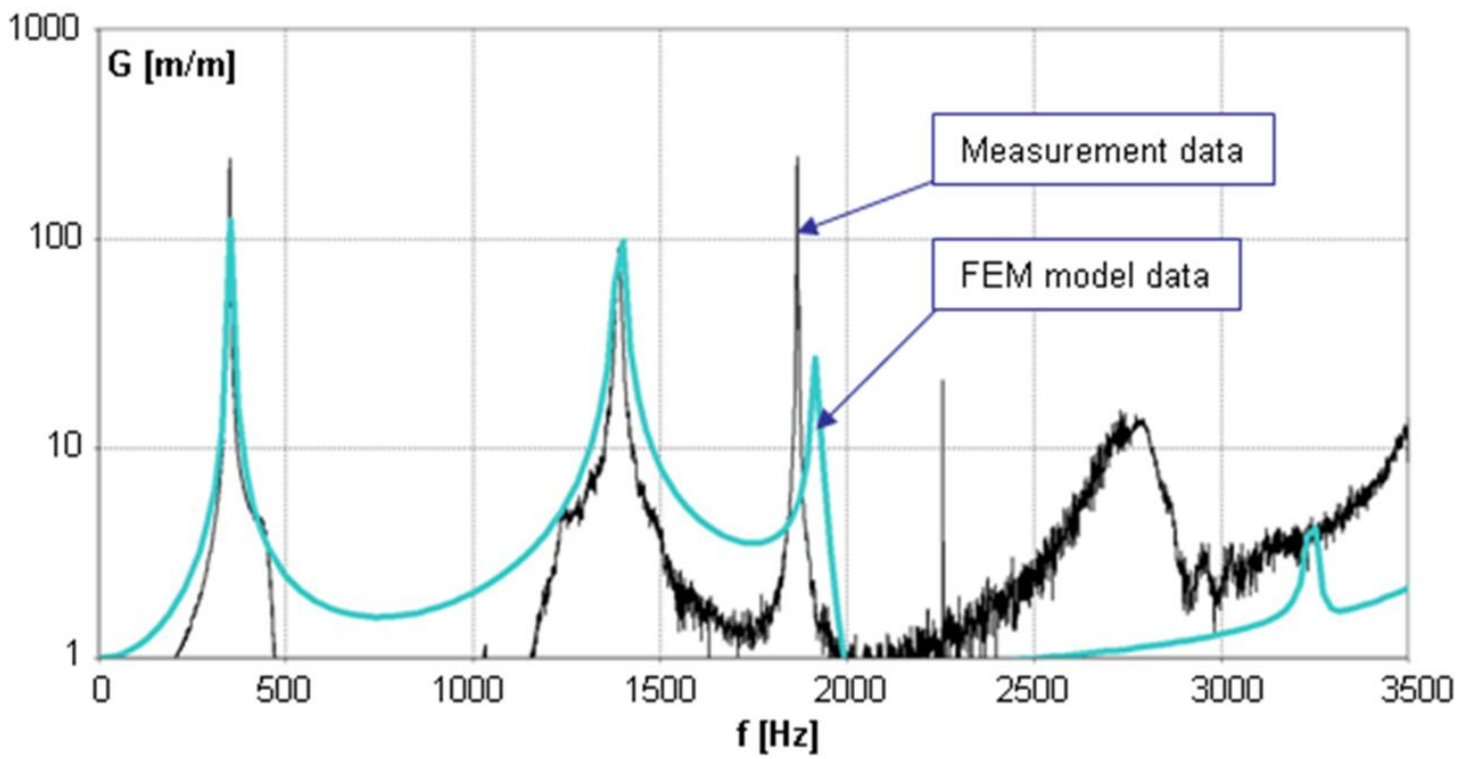

Fig. 14. Frequency responce of steel compressor blade

Internal damping of blade materials originates from the energy dissipation is associated with microstructure defects, such as grain boundaries and impurities; thermoelastic effects caused by local temperature gradients resulting from nonuniform stresses, as in vibrating beams; eddy current effects in ferromagnetic materials; dislocation motion in metals; and chain motion in polymers (fan blades). Several models have been employed to represent energy dissipation caused by internal damping. This variety of models is primarily a result of the vast range of engineering materials; no single model can satisfactorily represent the internal damping characteristics of all materials. Nevertheless, two general types of internal damping can be identified:

- viscoelastic damping, and

- hysteretic damping. 
The latter term is actually a misnomer, because all types of internal damping are associated with hysteresis loop effects [40]. The stress $\sigma$ and strain $\varepsilon$ relations at a point in a vibrating continuum possess a hysteresis loop, such as the one shown in Figure 15.

The area of the hysteresis loop gives the energy dissipation per unit volume of the material, per single stress cycle. This is called the per unit-volume damping capacity, and is denoted by $d$. It is clear that $d$ is given by the cyclic integral

$$
d=\oint \sigma d \varepsilon
$$

For a linear viscoelastic material, the stress - strain relationship is given by a linear differrential equation with respect to time, with constant coefficients. A commonly employed relationship is

$$
\sigma=E \varepsilon+E^{*} \frac{d \varepsilon}{d t}
$$

which is known as the Kelvin - Voigt model.

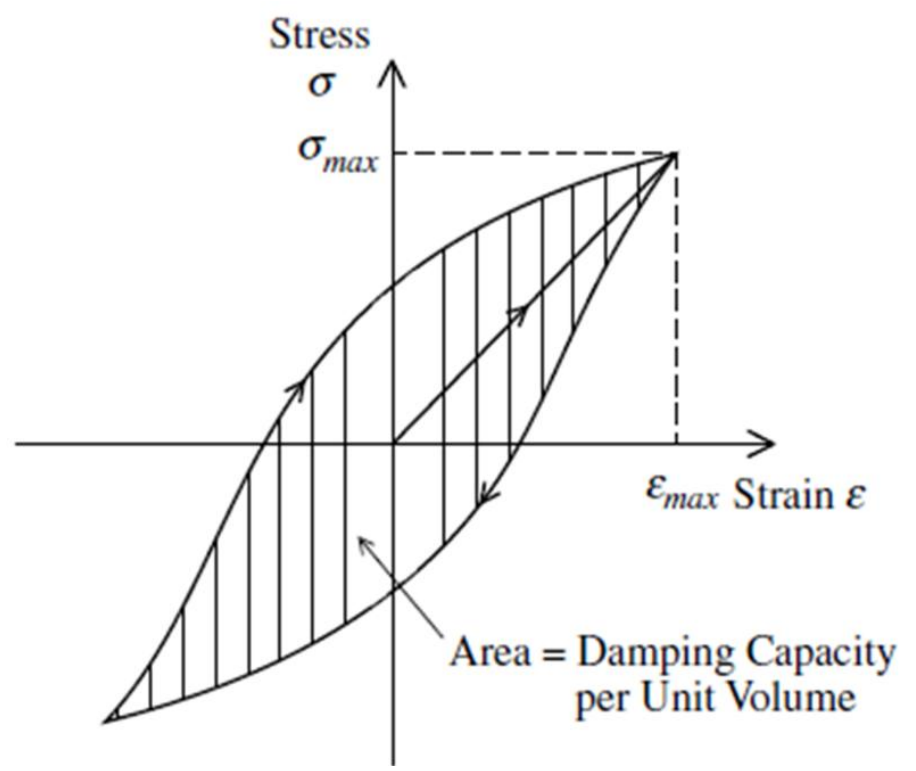

Fig. 15. A typical hysteresis loop for mechanical damping

In Equation 15, $E$ is Young's modulus and $E^{*}$ is a viscoelastic parameter that is assumed to be time independent. The elastic term $E \varepsilon$ does not contribute to damping, and, as noted before, mathematically, its cyclic integral vanishes. Consequently, for the Kelvin - Voigt model, damping capacity per unit volume is

$$
d_{V}=E^{*} \int \frac{d \varepsilon}{d t} d \varepsilon \pi
$$

For a material that is subjected to a harmonic (sinusoidal) excitation, at steady state, strain is:

$$
\varepsilon=\varepsilon_{\max } \cos \omega t
$$

When Equation 17 is substituted in Equation 16:

$$
d_{V}=\pi \omega E^{*} \varepsilon_{\max }^{2}
$$

Now, $\varepsilon=\varepsilon_{\max }$ when $\mathrm{t}=0$ in equation 17 , or when $d \varepsilon / d t=0$. The corresponding stress, according to Equation 15 , is $\sigma_{\max }=E \varepsilon_{\max }$. It follows that:

$$
d_{V}=\frac{\pi \omega E^{*}}{E^{2}} \sigma_{\max }^{2}
$$


These expressions for $d \mathrm{v}$ depend on the frequency of excitation, $\omega$.

Apart from the Kelvin - Voigt model, two other models of viscoelastic damping are also commonly used. These are the Maxwell model, which describes magneto-mechanical damping, given by:

$$
\sigma+c_{s} \frac{d \sigma}{d t}=E^{*} \frac{d \varepsilon}{d t}
$$

and the standard linear solid model given by:

$$
\sigma+c_{s} \frac{d \sigma}{d t}=E \varepsilon+E^{*} \frac{d \varepsilon}{d t}
$$

The standard linear solid model represents a combination of the Kelvin - Voigt model and the Maxwell model, and is the most accurate of the three.

For some types of materials, the damping force does not significantly depend on the frequency of strain oscillation (or frequency of harmonic motion) [40]. This type of internal damping is known as hysteretic damping.

Damping capacity per unit volume $d_{\mathrm{h}}$ for hysteretic damping is also independent of the frequency of motion and can be represented by:

$$
d_{h}=J \sigma_{\max }^{n}
$$

A simple model that satisfies Equation 22, for the case of $n=2$; is given by:

$$
\sigma=E \varepsilon+\frac{\widetilde{E}}{\omega} \frac{d \varepsilon}{d t}
$$

which is equivalent to using a viscoelastic parameter, $E^{*}$ and depends on the frequency of motion in Equation 15 according to $E^{*}=\widetilde{E} / \omega$.

Given harmonic motion at frequency $\omega$; with the material strain given by:

$$
\varepsilon=\varepsilon_{0} \cos \omega t
$$

Equation 23 becomes:

$$
\sigma=E \varepsilon_{0} \cos \omega t-\widetilde{E} \varepsilon_{0} \sin \omega t=E \varepsilon_{0} \cos \omega t+\widetilde{E} \varepsilon_{0} \cos \emptyset t+0,5 \pi^{-}
$$

Note that the material stress has two components, as given by the right-hand side of Equation 25. The first component corresponds to the linear elastic behavior of the material and is in phase with the strain. The second component of stress, which corresponds to hysteretic damping, is $90^{\circ}$ out of phase. A convenient mathematical representation is possible using the usual complex form of the response according to:

$$
\varepsilon=\varepsilon_{0} e^{j \omega t}
$$

Then, Equation 23 becomes:

$$
\sigma=\boldsymbol{E}+j \widetilde{E} \bar{\xi}
$$

It follows that this form of simplified hysteretic damping may be represented by using a complex modulus of elasticity, consisting of a real part which corresponds to the usual linear elastic (energy storage) modulus (or Young's modulus) and an imaginary part, which corresponds to the hysteretic loss (energy dissipation) modulus.

By combining Equation 15 and Equation 23, a simple model for combined viscoelastic and hysteretic damping may be given by:

$$
\sigma=E \varepsilon+\left(E^{*}+\frac{\widetilde{E}}{\omega}\right) \frac{d \varepsilon}{d t}
$$


The equation of motion for a system whose damping is represented by Equation 28 can be deduced from the pure elastic equation of motion by simply substituting $E$ by the operator:

$$
E+\left(E^{*}+\frac{\widetilde{E}}{\omega}\right) \frac{\partial \varepsilon}{\partial t}
$$

in the time domain.

\subsection{Magneto-mechanical damping}

Applying a stress to a ferromagnetic blade causes a variation in magnetization due to the magneto-elastic coupling, which results in the so-called " $\Delta \mathrm{E}$ effect" (i.e. an apparent reduction of Young's modulus below the purely elastic value found in the magnetically saturated state), Figure 16 , and also in a related dissipation of mechanical energy during loading/unloading or in the case of vibration. The latter effect can give rise to a strong magneto-mechanical damping with stressdependent and stress-independent components [41].

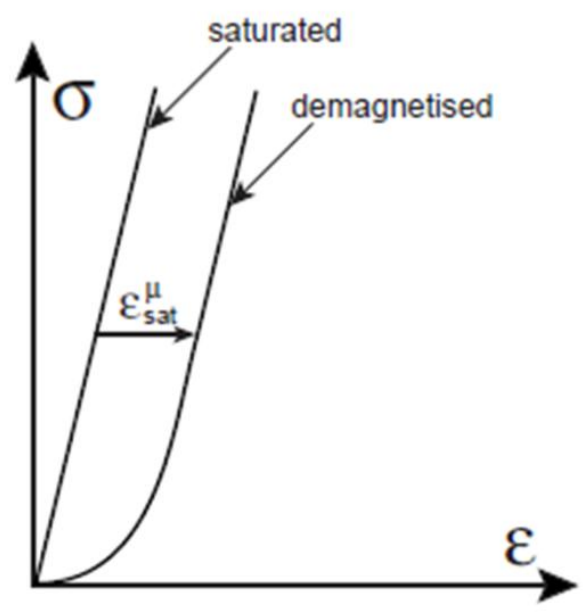

Fig. 16. $\Delta E$ effect in ferromagnetic blade

Experiments show that ferromagnetics have a higher internal friction than other metals because of the electro-magnetic phenomena resulting from the application of elastic fields. Considering five main contributions to the total energy of a ferromagnetic without an external field (exchange energy $\mathrm{W}_{\mathrm{ex}}$, magnetocrystalline anisotropy energy $\mathrm{W}_{\mathrm{k}}$, magneto-elastic (or magnetostrictive) energy $\mathrm{W}_{\lambda}$, magnetostatic energy $\mathrm{W}_{\mathrm{m}}$, energy of magnetic domain walls $\mathrm{W}_{\mathrm{w}}$ ), four main mechanisms of magneto-mechanical damping may be defined [41]:

- magnetoelastic hysteresis damping, $Q_{h}^{-1}$

- macroeddy-current damping, $Q_{a}^{-1}$

- microeddy-current damping $Q_{u}^{-1}$

- damping at magnetic transformation $Q_{P h T}^{-1}$

Therefore, the total magneto-mechanical damping $Q_{m}^{-1}$ in the ferromagnetic blade can be considered as a sum of these components:

$$
Q_{m}^{-1}\left(\omega, T \equiv Q_{h}^{-1} \mathbf{c}, \omega, T+Q_{a}^{-1}\left(, T+Q_{\mu}^{-1}\left(, T+Q_{P h . T}\right.\right.\right.
$$

Where: contrary to $Q_{a}^{-1}$ and $Q_{u}^{-1}$, the hysteretic contribution $Q_{h}^{-1}$ depends on the strain amplitude. The damping $Q_{m}^{-1}$ is also dependent on the load frequency, material temperature, and initial conditions (micro- and macrostructure, magnetization, residual stress). 


\section{Magneto-elastic hysteresis damping}

Magneto-elastic hysteresis damping $Q_{h}^{-1}$ is the most important and powerful type of damping in the ferromagnetic blade. It is due to the stress-induced motion of non- $180^{\circ}$ domain walls (while the $180^{\circ}$ walls are stress-intensive), including irreversible Barkhausen jumps beyond a critical stress $\tau_{\mathrm{cr}}$. At low shear stresses $\tau$ or shear strains $\gamma$ (i.e. in the Rayleigh region of the magnetization curve), the hysteretic energy dissipated is [41]:

$$
\Delta W_{h}=\frac{4}{3} \frac{d \boldsymbol{F}^{-1}}{d \tau} \tau^{3}, \text { so that } Q_{h}^{-1}=\frac{\Delta W_{h}}{2 \pi W}
$$

The fact that the vibration energy $W$ varies with $\tau^{2}$ implies a linear amplitude dependence of internal friction. For higher stresses, however, the hysteretic losses $\Delta W_{\mathrm{h}}$ no longer increase with $\tau^{3}$ but with a stress-dependent exponent $0<n<3$, and finally reach a saturation level; consequently $Q_{h}^{-1}$ shows a maximum as a function of stress or strain. The position and height of the amplitudedependent damping maximum of $Q_{h}^{-1}$ can be used to determine the level of these internal stresses [41]. The total magneto-mechanical damping $Q_{m}^{-1}$ is nonlinear [42], so damping coefficient $c$ in Equation 6 and the FEM model are nonlinear too.

\section{CONCLUSIONS}

1. During 15 years of using the tip timing method in the Polish Armed Forces:

- The statistical mean time between fatigue break-offs of blades has been increased (nine times for calendar-based data, and five times on the hourly basis). Since 1991 no fatigue crack of any compressor blade in the SO-3 engines has been found.

- The problems resulting from maladjustment of the fuel system and latent defects of subsystems have been eliminated.

- Five SO-3 engines have been taken out of service due to excessive errors in shapes of the blades.

2. The shape of the cracked blade resonant curve is described by the blade material and conditions existing on the edge of the crack gap. The characteristic curve is sloped into left for the crack with material weakening. On the other hand, for the gap with material hardening, the curve is sloped into right. Asymmetry of resonant curve was not found on the notched blade.

3. The mode frequency of cracked blade depends on the condition of the crack edge. For the titanium blade with a $12 \mathrm{~mm}$ crack and hardening stiffness characteristic, a vibration frequency of the first mode was considered as efficient under technical specification conditions.

4. Nonlinear properties of a crack blade are fundamental for the prognosis of the crack propagation rate and for the determination of the safe prognosis horizon. These modal symptoms of material damage are correlated with magnetic symptoms.

5. Diagnostic symptoms of the material weakening occur before:

- the $1^{\text {st }}$ mode frequency decrease by $3 \mathrm{~Hz}$, the symptom of airfoil crack according to current technical and overhaul requirements;

- an open crack, identified during the engine overhaul with a classical NDT method.

The study has been prepared under the research project no. ON 504000534 funded by the Ministry of Science and Higher Education in the years 2008-2010. 


\section{REFERENCES}

[1] US Patents 2575710 (1951), 3058339 (1962), 3467358 (1969), 3597963 (1971), 4153388 (1979), 4593566 (1986), 4827435 (1989), 5148711 (1992), 5479826 (1996), 6094989 (2000)

[2] Witos, M. (1994). Diagnosing of technical condition of turbine engine compressor blades using non-contact vibration measuring method. Dissertation, ITWL Warszawa (pol.)

[3] von Flotow A., Drumm, M. J. (2002). Engine Sensing Technology Hardware \& Software to Monitor Engine Rotor Dynamics Using Blade Time-Of-Arrival and Tip Clearance. Hood River, OR, USA, www.hoodtech.com

[4] Washburn, R. (2004). Amplitude and Phase Variations Associated with Low Order Resonance Responses Subjected to Time Varying Excitation Sources. Proc. of $9^{\text {th }}$ National Turbine Engine High Cycle Fatigue Conference. March 2004, North Carolina.

[5] Zielinski, M., Ziller, G. (2005). Noncontact Crack Detection on Compressor Rotor Blades to Prevent Further Damage after HC-Failure. RTO MP-AVT-121 Meeting Proceedings, NATO, paper 19. (www.mtu.de)

[6] Witos, M., Szczepanik, R. (2005). Turbine Engine Health/Maintenance Status Monitoring with Use of Phase-Discrete Method of Blade Vibration Monitoring. RTO-MP-AVT -121 Meeting Proceedings, NATO, paper 2.

[7] Duan, F., Fang, Z., Sun, Y. \& Ye, S. (2005). Real-time Vibration Measurement Technique Based on Tip-timing for Rotating Blades. Opto-Electronic Engineering. 30(1), 29-31.

[8] Ayes, B.W., Arnold, S., Vining, Ch. \& Howard, R. (2005). Application of Generation 4 Noncontact Stress Measurement System on HCF Demonstrator Engines. Proc. of $10^{\text {th }}$ National Turbine Engine High Cycle Fatigue (HCF) Conference. Dayton, USA.

[9] http://www.agilismeasurementsystems.com

[10] Brouckaert, J.F. (editor). Tip Timing and Tip Clearance Problems in Turbomachinary. Lecture Series 3-2007, VKI Belgium, 2007.

[11] Witos, M. (2008). Turbine Engine Health/Maintenance Status Monitoring with Use of Tip Timing Method. Proc. of $4^{\text {th }}$ European Workshop on Structural Health Monitoring 2008. DEStech Publication Inc., pp. 157-164.

[12] Witos, M.(2008). On the Modal Analysis of a Cracking Compressor Blade. Research works of AFIT, Issue 23, pp. 21-36

[13] Vlasov, V.T., Dubov, A.A. (2004). Physical Bases of the Metal Magnetic Memory Method. Moscow: ZAO "Tisso" Publishing House.

[14] Dubow, A. A., Dubow, Al. A., Kolokolnikow, S. M. (2004). Metoda magnetycznej pamięci metalu (MPM) i przyrzady kontroli. Warszawa: RESURS.

[15] Ding, X., Li, J., Li, F. \& Pang, X. (2008). Magnetic Memory Inspection of High Pressure Manifoolds. $17^{\text {th }}$ World Conference on Nondestructive Testing, 25-28 Oct 2008, Shanghai, China.

[16] Lisiecki, J. (2004). O metodzie magnetycznej pamięci materiału. Prace Naukowe ITWL, Warszawa, Zeszyt 18, s. 51-84.

[17] Liu, Q., Lin, J., Chen, M., Wang, C., Wang, G., Zhao, F. Z., Geng, Y. \& Zheng, Ch. (2008). A Study of Inspecting the Stress on Downhole Metal Casing in Oilfields with Magnetic Memory Method. $17^{\text {th }}$ World Conference on Nondestructive Testing, 25-28 Oct 2008, Shanghai, China.

[18] Radziszewski, A. (2001). Doświadczenia z kontroli urządzeń $i$ ich oprzyrządowania w polskich przedsiębiorstwach z zastosowaniem metody magnetycznej pamięci metalu. Materiały 30 KKBN, Szczyrk. Zeszyty Problemowe. Badania Nieniszczące, Nr 6 (2001), s. 165- 170. 
[19] Roskosz M. (2005). Zastosowanie metody magnetycznej pamięci metalu do badań wirników sprężarek. Problemy i innowacje w remontach energetycznych. PIRE 2005. VIII Konferencja naukowo-techniczna, Szklarska Poręba, s. 259-270.

[20] Shi, Ch-L., Dong, Sh-Y., He, P. \& Xu, B-Sh. (2008). Influence of Stress Concentration Factor on Magnetic Memory Effect of Steel Samples under Dynamic Tension Load. $17^{\text {th }}$ World Conference on Nondestructive Testing, 25-28 Oct 2008, Shanghai, China.

[21] Witoś, M., Wiśnoch, M. (2009). Metoda magnetycznej pamięci metalu $w$ diagnozowaniu techniki lotniczej. XV Seminarium „Nieniszczące badania materiałów”, 10-13 marca 2009, Zakopane. (http://www.ndt-imbn.com/portal)

[22] Shaniavski, A.A. (2007). Modeling of fatigue cracking of metals. Synergetics for aviation. Publishing House of Scientific and Technical Literature "Monography", Ufa (ros.).

[23] Shaniavski, A.A. (2003). Tolerance Fatigue of Aircraft Components. Synergetics in engineering applications. Publishing House of Scientific and Technical Literature "Monography", Ufa (ros.).

[24] Murakami, Y., Nomoto, T. \& Ueda, T. (1999). Factors Influencing the Mechanism of Superlong Fatigue Failure in Steels. Fatigue and Fracture of Engineering Materials and Structures. Vol. 22, pp. 581-590.

[25] Murakami, Y., Takada, Y. \& Toriyama, T. (1998). Super-long life tension-compression fatigue properties of quenched and tempered $0.46 \% \mathrm{C}$ steel. International Journal of Fatigue. Vol. 16, pp. 661-667.

[26] Sakai, T. (2009). Review and prospects for current studies on Very High Cycle Fatigue of metal materials for machine structural use. Journal of Solid Mechanics and Materials Engineering. 3(3), 425-439.

[27] Witek, L. (2009). Experimental crack propagation analysis on the compressor blades working in high cycle fatigue condition. In A. Niepokólczycki (editor), Fatigue of Aircraft Structures Monographic Series (pp.195-204) Poland, Warsaw: Institute of Aviation Scientific Publications.

[28] http://www.polytec.com

[29] http://www.mtiintruments.com

[30] www.vibrationresearch.com/software

[31] Witoś, M. (2010). Increasing the durability of turbine engine components through active diagnostics and control. Research works of AFIT, Issue 29 (pol.)

[32] Ostrovsky, L.A., Johnson, P.A. (2001). Dynamic nonlinear elasticity in geomaterials. Revista del Nuovo Cimento. 24(7), 1-46. http://www.lanl.gov/orgs/ees/ees11/ geophysics/ nonlinear/2001/nrc8730.pdf

[33] Ferreira, J. V. (1998). Dynamic Response Analysis of Structure with Nonlinear Components. Thesis, University of London.

[34] Buch, A. (1964). Zagadnienia wytrzymałości zmęczeniowej. Warszawa: PWN.

[34] Tae-Kyu Lee, J.W. Morris, Jr., Seungkyun Lee \& J. Clarke. Detection of fatigue damage prior to crack initiation with scanning SQUID microscopy. Review of Progress in Quantitative Nondestructive Evaluation, Vol. 25.

[35] Altherton, D.L., Jiles, D.C. (1986). Effects of stress on magnetization. NDT International. 19(1), pp. 15-19.

[36] Własow, W.T., Dubow, A.A. (2007). Fizyczeskaja teoria procesa ,deformacijarazruszenije. Czast I. Fiziczeskije kriterii predelnych sostojanij metałła. Moskwa.

[37] Birss, R.R., Faunce, C.A. (1971). Stress-Induced Magnetization in Small Magnetic Fields. Journal de Physique, Colloque C I, supplément au n ${ }^{\mathrm{O}} 2-3$, Tome 32, Février-Mars, page C 1 686-688.

[38] Robertson, I.M. (1991). Magneto-Elastic Behaviour of Steels for Naval Applications, MRL Technical Report, DSTO Materials Research Laboratory. (MRL-TR-90-27) 
[39] Atherton D.L., Sudersena Rao, T., de Sa V., Schönbachler M. (1988). Thermodynamic Correlation Tests Between Magnetostrictive and Magnetomechanical Effects in $2 \% \mathrm{Mn}$ Pipeline Steel. IEEE Transactions on Magnetics. 24(5), pp. 2177-2180.

[40] De Silva, C.W. (2007). Vibration Damping, Control and Design. Taylor \& Francis

[41] Blanter, M.S., Golovin, I.S., Neuhäuser, H. \& Sinning, H.-R. (2007). Internal Friction in Metallic Materials. A Handbook. Berlin: Springer-Verlag.

[42] Gui, Y.S., Wirthmann, A., Macking, N., Hu, C.-M. (2009). Direct measurements of nonlinear ferromagnetic damping via the intrinsic foldover effect. Phys. Rev. B80, 060402(R) 